University of Nebraska - Lincoln

DigitalCommons@University of Nebraska - Lincoln

1997

\title{
A Simulation Model Including Ovulation Rate, Potential Embryonic Viability, and Uterine Capacity to Explain Litter Size in Mice: I. Model Development and Implementation
}

\author{
E. L. de A. Ribeiro \\ Universidade Estuadual de Londrina \\ Merlyn K. Nielsen \\ University of Nebraska-Lincoln, mnielsen1@unl.edu \\ Gary Bennett \\ University of Nebraska-Lincoln, gary.bennett@ars.usda.gov \\ Kreg A. Leymaster \\ University of Nebraska-Lincoln, kleymaster2@unl.edu \\ Follow this and additional works at: https://digitalcommons.unl.edu/animalscifacpub \\ Part of the Animal Sciences Commons
}

de A. Ribeiro, E. L.; Nielsen, Merlyn K.; Bennett, Gary; and Leymaster, Kreg A., "A Simulation Model Including Ovulation Rate, Potential Embryonic Viability, and Uterine Capacity to Explain Litter Size in Mice: I. Model Development and Implementation" (1997). Faculty Papers and Publications in Animal Science. 502.

https://digitalcommons.unl.edu/animalscifacpub/502

This Article is brought to you for free and open access by the Animal Science Department at DigitalCommons@University of Nebraska - Lincoln. It has been accepted for inclusion in Faculty Papers and Publications in Animal Science by an authorized administrator of DigitalCommons@University of Nebraska - Lincoln. 


\title{
A Simulation Model Including Ovulation Rate, Potential Embryonic Viability, and Uterine Capacity to Explain Litter Size in Mice:
} I. Model Development and Implementation ${ }^{1}$

\author{
E. L. de A. Ribeiro*,2, M. K. Nielsen*,3, G. L. Bennett', and K. A. Leymastert \\ *Department of Animal Science, University of Nebraska-Lincoln, Lincoln 68583-0908 and
} ${ }^{\dagger}$ Roman L. Hruska U. S. Meat Animal Research Center, ARS, USDA, Clay Center, NE $68933-0166$

\begin{abstract}
Litter size in mice was studied using a model including ovulation rate, potential embryonic viability, and uterine capacity. Simulated results were compared with experimental results from a selection experiment with mice. The four criteria of selection were selection on number born (LS), selection on an index of ovulation rate and ova success (IX), selection on number born to unilaterally ovariectomized females (UT), and unselected control (LC). Comparisons were made to statistics of the base generation and to responses after 13 generations of selection. Phenotypic and genetic statistics for uterine capacity were generated so that simulations produced the experimental means, standard deviations, and correlations between left and right litter size, as well as
\end{abstract}

responses in number born using the LS, IX, and UT criteria. Statistics for the simulated data generally agreed with observed values. Simulated heritability in the base generation for uterine capacity was .065. Experimental and simulated responses per generation in litter size through 13 generations of selection were .15 and $.16, .17$ and .18 , and .10 and .11 for LS, IX, and UT, respectively. Simulated responses in uterine capacity after 13 generations were $2.19,1.60$, and 3.40 for LS, IX, and UT, respectively. Simulated means for the base generation were 13.22 and 16.30 for ovulation rate and uterine capacity, respectively. Uterine capacity was an important component of the variability in litter size; however, ovulation rate was the more limiting component.

Key Words: Mice, Selection, Litter Size, Simulation, Uterus, Ovulation Rate

\section{Introduction}

Earlier attempts to explain litter size used a model including only ovulation rate and the proportion of ova represented by offspring at birth (see J ohnson et al., 1984). This model has been explored recently in simulation of sheep litter size (Perez-Enciso et al., 1994).

A different model in which ovulation rate, potential embryonic viability, and uterine capacity interact to explain litter size at birth was proposed by Bennett and Leymaster (1989). Bennett and Leymaster (1989) developed their model using swine data from several reports.

\footnotetext{
${ }^{1}$ Published as paper no. 11474, J ournal Ser. Nebraska Agric. Res. Div., Univ. of Nebraska, Lincoln 68583-0908.

${ }^{2}$ Current address: Departamento de Zootecnia, Universidade Estuadual de Londrina, Londrina-PR, 86051-970, Brazil.

${ }^{3}$ To whom correspondence should be addressed: A218 Animal Science.

Received April 1, 1996.

Accepted October 16, 1996.
}

An analogous model for litter size in mice is more complicated because the duplex reproductive tract of mice prohibits migration of embryos between uterine horns. If we are able to generate means and variances for uterine capacity and duplicate the observed statistics for litter size found in mice data and mimic observed responses to selection, then the model suggested by Bennett and Leymaster (1989) for swine would be extended to a second species. Thus, the primary objective of this study was to integrate ovulation rate, potential embryonic viability, and uterine capacity into a model of litter size in mice. A secondary objective was to use the model to simulate means and variances of uterine capacity in mice selected on alternative criteria to increase litter size.

\section{Materials and Methods}

Phenotypic Simulation Model. The model proposed for pigs by Bennett and Leymaster (1989) is illustrated in Figure 1 . Ovulation rate is first reduced by the probability of embryos surviving independent from 
OVULATION RATE (Normal)

$$
\mid \begin{gathered}
x \text { POTENTIAL EMBRYONIC VIABILITY } \\
\text { (Binomial) }
\end{gathered}
$$

POTENTIALLY VIABLE EMBRYOS

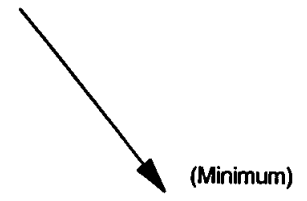

UTERINE CAPACITY (Normal)

LITTER SIZE

Figure 1. Simulation model for litter size in pigs used by Bennett and Leymaster (1989).

uterine capacity to yield potentially viable embryos, and the latter can be further reduced due to uterine capacity. Litter size at birth is the minimum of potentially viable embryos and uterine capacity. The model used here for mice (Figure 2 ) was an extension of the one cited above. Mice have a duplex uterus; consequently, there is little chance of embryos migrating from one uterine horn to the other uterine horn (McLaren and Michie, 1954). In fact, Clutter et al. (1994) reported no evidence of migration of embryos to the opposite uterine horn in a study involving over 1,900 unilaterally ovariectomized females. Due to this difference in the uterine anatomy, the model for mice had two modifications: 1) total ovulation rate was divided into right and left ovulation rates and 2 ) uterine capacities were simulated for right and left sides. A correlation between right and left uterine capacities was set. The other components of the model were left uncorrelated.

The algorithm used to simulate litter size and the other components followed the one used by Bennett and Leymaster (1989), but with the modifications cited above introduced. Total ovulation rate was calculated by sampling a standard normal variate, which was multiplied by the standard deviation of ovulation rate, and the product was added to the mean ovulation rate. Total ovulation rate was split into left and right ovulation rates using a binomial probability. Then, left and right ovulation rates were reduced to left and right potentially viable embryos using a binomial probability.

Next, left and right uterine capacities were simulated using normal distributions. A standard normal variate was sampled and multiplied by the standard deviation of right uterine capacity, and then the product was added to the mean uterine capacity for the right side. The left-side uterine capacity started from the same normal variate, used the standard deviation of left uterine capacity, and accounted for a correlation between right and left sides.

Total, right, and left ovulation rates, right and left potentially viable embryos, and right and left uterine capacities were rounded to integer values, and if values smaller than one were generated, these values were set to one. Litter size for each distinct side was the minimum of potentially viable embryos and uterine capacity for that side. Total litter size was the sum of left and right litter sizes.

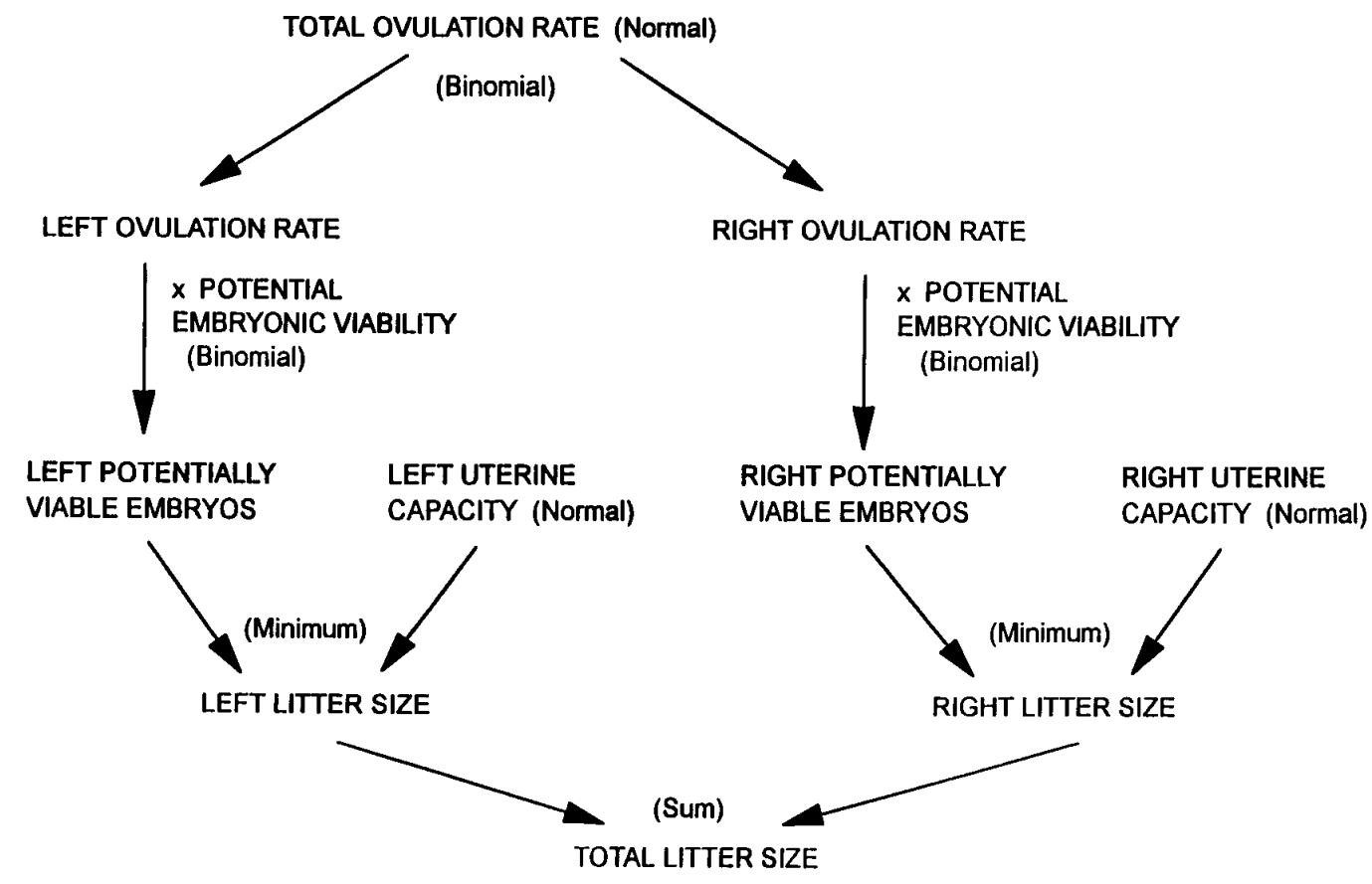

Figure 2. Simulation model for litter size in mice. 
Table 1. Phenotypic means and SD used to simulate litter size in mice

\begin{tabular}{|c|c|c|c|c|c|c|}
\hline \multirow[b]{2}{*}{ Populationa } & \multicolumn{2}{|c|}{ Ovulation rate ${ }^{b}$} & \multicolumn{2}{|c|}{ Right uterine capacity } & \multicolumn{2}{|c|}{ Left uterine capacity } \\
\hline & Mean & SD & Mean & SD & Mean & SD \\
\hline Base generation & 13.20 & 1.89 & 8.88 & 4.00 & 7.40 & 3.33 \\
\hline LC-13 & 12.27 & 1.76 & 8.40 & 3.78 & 8.03 & 3.61 \\
\hline LS-13 & 14.15 & 2.03 & 9.80 & 4.41 & 9.80 & 4.41 \\
\hline IX-13 & 14.25 & 2.05 & 11.88 & 5.35 & 9.90 & 4.46 \\
\hline UT-13 & 12.65 & 1.81 & 11.64 & 5.24 & 9.70 & 4.37 \\
\hline
\end{tabular}

${ }^{a} \mathrm{LC}-13=$ Generation 13 of the unselected control; LS-13 = Generation 13 of selection for litter size; IX-13=Generation 13 of selection for the index; UT-13 = Generation 13 of selection for uterine capacity.

bStatistics of ovulation rate for the base population were published by Clutter et al. (1990). Means of ovulation rate for generation 13 were published by Gion et al. (1990); standard deviations were estimated using the same data set.

Phenotypic Statistics Used in the Simulation. To implement the model, we needed phenotypic statistics for ovulation rate, potential embryonic viability, and uterine capacity for both reproductive sides. Data from a selection experiment, conducted at University of Nebraska-Lincoln, using different criteria to increase litter size were used. Statistics of the base population were published by Clutter et al. (1990) and for Generation 13 by Gion et al. (1990).

The criteria of selection used in that experiment were: 1) IX: selection on an index of components of litter size $(I=1.21 \times$ ovulation rate $+9.05 \times$ ova success [proportion of ova represented by pups born]); 2) UT: selection on number born to unilaterally ovariectomized females; 3) LS: selection on total number born; and 4) LC: unselected control. Details concerning methods of selection were presented by Clutter et al. (1990) and Gion et al. (1990).

Table 1 contains the phenotypic statistics used in the simulation. Ovulation rate parameters in the base population were based on statistics from 881 observations. In Generation 13, the number of observations for generating statistics varied between 212 and 270 for all four selection populations. Simulated phenotypic standard deviations for ovulation rate were determined using a pooled estimate of the CV for ovulation rate of $14.32 \%$.

The probability of an ovulation being on the right ovary was .52, consistent with many experimental data sets from our laboratory. Probabilities of embryos surviving to implantation, which were used to obtain potentially viable embryos, were estimated from experimental data on number of embryos at d 6 of gestation relative to number of corpora lutea (Ribeiro et al., 1996) measured in these same selection populations. Because there were not clear differences among criteria, the probabilities from the experimental work were averaged over criteria and side. The resulting probability, .87, was then increased to .92, and .92 was used in all simulations. The probability was adjusted upward because the stage of measurement $(d \quad 6)$ in the experimental work may have been affected by uterine capacity, and the adjusted probability gave better agreement between simulated and observed data.
Records of 10,000 animals for each case were simulated using SAS (1990). Means and standard deviations (Table 1) and correlations for uterine capacity were generated by iteration (i.e., these values were varied successively until statistics for the simulated data for litter size arrived at the closest agreement with observed means, standard deviations, and correlations between left and right litter sizes). The lowest mean uterine capacities that gave the best fit were used; this also forced the standard deviations for uterine capacity to the lowest values. The best overall CV for uterine capacity was $45.0 \%$ for both sides. Likewise, the best correlation between right and left uterine capacity was .40; this value was used in all simulations.

Simulation Model Using Genetic Components. After phenotypic statistics had been established, genetic statistics were derived by an iterative process, taking into consideration the response in number born observed by Gion et al. (1990) after 13 generations of selection. Ovulation rate and uterine capacity were assumed to be composed of additive genetic and random environmental components. The probability of embryos surviving to implantation (i.e., potential embryonic viability) was assumed to be nongenetic. Bolet (1986) stated that for most cases embryonic survival does not have an additive genetic component. Although genetic variability in prenatal survival has been observed (Bradford, 1969, 1979), Bennett and Leymaster (1990a) suggested that it may be realized through the interaction between ovulation rate and uterine capacity. Gama et al. (1991) estimated genetic statistics for embryonic (fetal) survival measured at $\mathrm{d} 50$ of gestation in pigs. As a trait of the embryo, heritability of direct effects ranged from .001 to .038 , and heritability of maternal effects ranged from .006 to .044 . Heritability of embryonic survival as a trait of the dam ranged from .087 to .102.

The genetic correlation between left and right uterine capacity was set to .92, as estimated in later generations of these populations of mice ( $\mathrm{Nielsen}$ et al., 1996). The correlation between ovulation rate and uterine capacity was assumed to be zero. Nevertheless, initially several levels of the correlation between the two components were evaluated (not presented 
Table 2. Phenotypic and genetic statistics used in the simulation of litter size for the base population

\begin{tabular}{|c|c|c|c|c|c|c|}
\hline \multirow[b]{2}{*}{ Trait } & \multirow[b]{2}{*}{ Mean } & \multirow{2}{*}{$\frac{\text { Phenotypic }}{\text { SD }}$} & \multirow{2}{*}{$\frac{\text { Genetic }}{\text { SD }}$} & \multicolumn{3}{|c|}{ Correlations and heritabilities $^{a}$} \\
\hline & & & & OR & RUC & LUC \\
\hline Ovulation rate (OR) & 13.20 & 1.89 & .945 & .250 & .000 & .000 \\
\hline Right uterine capacity (RUC) & 8.88 & 4.00 & 1.020 & .000 & .065 & .920 \\
\hline Left uterine capacity ( $L$ U C) & 7.40 & 3.33 & .849 & .000 & .400 & .065 \\
\hline
\end{tabular}

aHeritabilities on diagonal; genetic correlations above diagonal and phenotypic correlations below diagonal.

here), but results of the simulation model were not affected much by differing values of this correlation.

Genotypic values for total ovulation rate and right and left uterine capacity of sires and dams were derived in the same manner as the phenotypic values described earlier, but replacing phenotypic standard deviations and correlations with genetic ones. Daughter genotypic values were calculated as half of a sire plus half of a dam genotypic values, plus a Mendelian sampling component. Random environmental effects were generated using standard normal deviates and environmental standard deviations. A daughter's phenotypic value for a specific trait was calculated as the sum of the genotypic and environmental effects plus the average value for that trait.

Genetic statistics, derived through the iterative process of the simulation, and phenotypic means and standard deviations used in the genotypic simulation of litter size are presented in Table 2. To study the genetic statistics of all traits, simulated or calculated from simulated ones, a large design data set was simulated to reduce sampling errors. Seven hundred sires were simulated, each mated to 100 dams. Each dam had one daughter; thus, a total of 70,000 daughters were simulated in the base generation to estimate variance components. Given the balanced design, variance components were estimated using a nested model in PROC ANOVA of SAS (1990).

Simulated Selection. Records for 16,000 mice $(2,000$ sires, 2 dams per sire, 4 daughters per dam) simulated for the base population were used to start the selection process. Selections were simulated for 13 generations for the three criteria (IX, LS, UT). All generations were discrete. The mating design was the same as described above, in which two females were mated to a male; four daughters per litter were measured. Mass selection was practiced by which the litters of the 4,000 highest ranking females of 16,000 females measured were used to be dams of the next generation. The genotypic values of the 2,000 sires were randomly sampled from a mean genotypic value equal to that of the 4,000 dams in the previous generation.

As pointed out by Bennett and Leymaster (1990b), this type of simulation does not take into account the temporary effect of linkage disequilibrium on variances and covariances. However, they commented that this should not be a concern because low heritabilities and selection on dam's performance are expected to have a small effect on the disequilibrium. According to Villanueva and Kennedy (1990), when heritabilities are low and genetic correlations are close to zero or to one, changes in genetic parameters due to linkage disequilibrium are minimal.

\section{Results}

Phenotypic Model. Means for right uterine capacity were generally larger than means for left uterine capacity. The difference between right and left side for Generation 13 means ranged from .00 for the LS criterion to 1.98 for the IX criterion. All simulated selected lines had greater right and left uterine capacities than LC. Right means for IX, UT, and LS were $41.4,38.5$, and $16.7 \%$ greater than LC, respectively. Superiority for left means listed in the same order were $23.3,20.8$, and $22.0 \%$. Base generation and LC at Generation 13 means were similar, suggesting no genetic trend in uterine capacity after 13 generations of random selection. Although the lowest possible mean and standard deviation for uterine capacity were used, the generated CV was large (45.0\%).

Results of the phenotypic simulation are presented in Tables 3 and 4. Observed means and standard deviations for ovulation rate were used in the simulation and cannot be used to validate the model. Matching the simulated means, standard deviations, and correlation between sides for litter size with the experimental values was the criterion for completing the calibration. Simulated means and standard deviations of total, right, and left ovulation rate and litter size for all four criteria (LC, LS, IX, and UT) at Generation 13 and for the base generation agreed well with observed values. Means for total, right, and left ova successes were not input directly but, as a result of the ratio of litter size and ovulation rate, they matched the observed values as expected. Standard deviations of ova success, however, were not directly or indirectly used in the simulation process and can be used as one indication of how well the model simulates observed values. Indeed, simulated and observed standard deviations of ova success agreed very well in all five simulations.

Another way to validate the model is to check phenotypic correlations among the traits. Phenotypic correlations for the base generation and for LS at 
Table 3. Simulated and observed means and phenotypic standard deviations for reproductive traits of the base generation and Generation 13 of the unselected control (LC)

\begin{tabular}{|c|c|c|c|c|c|c|c|c|}
\hline \multirow[b]{3}{*}{ Trait $^{a}$} & \multicolumn{4}{|c|}{ Base generation } & \multicolumn{4}{|c|}{ LC-13 } \\
\hline & \multicolumn{2}{|c|}{ Observed $^{\mathrm{b}}$} & \multicolumn{2}{|c|}{ Simulated } & \multicolumn{2}{|c|}{ Observed ${ }^{c}$} & \multicolumn{2}{|c|}{ Simulated } \\
\hline & Mean & SD & Mean & SD & Mean & SD & Mean & SD \\
\hline TOR & 13.20 & 2.02 & 13.22 & 1.91 & 12.27 & 1.57 & 12.27 & 1.78 \\
\hline TLS & 10.52 & 3.04 & 10.51 & 2.71 & 9.98 & 2.40 & 9.96 & 2.50 \\
\hline TOS & .80 & .21 & .80 & .18 & .82 & .18 & .82 & .18 \\
\hline ROR & 6.87 & 2.03 & 6.82 & 2.06 & 6.26 & 1.86 & 6.34 & 1.97 \\
\hline LOR & 6.34 & 2.03 & 6.38 & 2.01 & 6.01 & 1.93 & 5.93 & 1.93 \\
\hline RLS & 5.66 & 2.19 & 5.53 & 2.08 & 5.17 & 2.00 & 5.15 & 1.97 \\
\hline LLS & 4.86 & 2.12 & 4.98 & 1.95 & 4.81 & 1.94 & 4.81 & 1.88 \\
\hline ROS & .83 & .22 & .82 & .22 & .83 & .20 & .83 & .22 \\
\hline LOS & .78 & .27 & .80 & .23 & .82 & .23 & .83 & .22 \\
\hline
\end{tabular}

aTOR = total ovulation rate; TLS =total litter size; TOS =total ova success; ROR = right ovulation rate; LOR =left ovulation rate; RLS = right litter size; LLS = left litter size; ROS = right ova success; LOS = left ova success.

bublished by Clutter et al. (1990).

cMeans were published by Gion et al. (1990) and standard deviations were estimated from the same data set.

Generation 13 are shown in Tables 5 and 6. The same statistics were also generated for LC, IX, and UT populations at Generation 13. Because statistics for the simulations had similar agreement to the observed statistics in all simulations, tables of correlations for these three populations are not presented. With very few exceptions all correlations in the simulated data agreed quite well in magnitude and sign with the observed values. The correlations in the simulated data between right and left ova success agreed the least with observed values. In general, for these traits, correlations in the simulated data were smaller.

Genetic Model. Initial heritability for total ovulation rate (.33) was the one estimate reported by Clutter et al. (1990) and for right and left uterine capacities was the realized heritability for total number born to unilaterally ovariectomized females (.08) reported by Gion et al. (1990). Although the model using these genetic parameters yielded phenotypic statistics for the base population similar to the ones simulated with the phenotypic model, responses to selection were much larger than the ones observed by Gion et al. (1990). Genetic parameters that yielded similar responses to the observed values are presented in Table 2.

Table 7 contains estimated genetic statistics and phenotypic correlations of the simulated base generation. There was not close agreement between these estimates and those reported by Clutter et al. (1990). For example, simulated heritability (.09) for total litter size was half the .18 reported by Clutter et al. (1990). Heritabilities of the components of litter size used in the simulation were smaller than those reported by Clutter et al. (1990). For total ovulation rate, the heritability used in the simulation was .25 and it was estimated as .24, but Clutter et al. (1990)

Table 4. Simulated and observed means and phenotypic standard deviations for reproductive traits after 13 generations of selection ${ }^{\mathrm{a}}$

\begin{tabular}{|c|c|c|c|c|c|c|c|c|c|c|c|c|}
\hline \multirow[b]{3}{*}{ Trait $^{b}$} & \multicolumn{4}{|c|}{ LS } & \multicolumn{4}{|c|}{ IX } & \multicolumn{4}{|c|}{ UT } \\
\hline & \multicolumn{2}{|c|}{ Observed } & \multicolumn{2}{|c|}{ Simulated } & \multicolumn{2}{|c|}{ Observed } & \multicolumn{2}{|c|}{ Simulated } & \multicolumn{2}{|c|}{ Observed } & \multicolumn{2}{|c|}{ Simulated } \\
\hline & Mean & SD & Mean & SD & Mean & SD & Mean & SD & Mean & SD & Mean & SD \\
\hline TOR & 14.2 & 2.0 & 14.2 & 2.0 & 14.3 & 1.9 & 14.3 & 2.1 & 12.6 & 1.7 & 12.7 & 1.8 \\
\hline TLS & 11.6 & 2.9 & 11.6 & 2.8 & 12.0 & 2.6 & 11.9 & 2.8 & 10.8 & 2.3 & 10.7 & 2.3 \\
\hline TOS & .82 & .18 & .82 & .17 & .84 & .17 & .84 & .17 & .86 & .16 & .85 & .15 \\
\hline ROR & 7.2 & 2.0 & 7.3 & 2.2 & 7.4 & 2.0 & 7.4 & 2.2 & 6.7 & 2.0 & 6.5 & 2.0 \\
\hline LOR & 7.0 & 2.3 & 6.8 & 2.1 & 6.9 & 2.0 & 6.9 & 2.1 & 5.9 & 2.0 & 6.1 & 2.0 \\
\hline RLS & 5.9 & 2.2 & 6.0 & 2.2 & 6.3 & 2.1 & 6.2 & 2.2 & 5.8 & 2.0 & 5.6 & 2.1 \\
\hline LLS & 5.7 & 2.3 & 5.6 & 2.1 & 5.6 & 2.1 & 5.7 & 2.1 & 4.9 & 1.9 & 5.1 & 2.0 \\
\hline ROS & .83 & .22 & .83 & .21 & .87 & .20 & .85 & .20 & .88 & .20 & .86 & .20 \\
\hline LOS & .82 & .21 & .84 & .21 & .82 & .21 & .84 & .21 & .84 & .20 & .85 & .21 \\
\hline
\end{tabular}

${ }^{\mathrm{a}} \mathrm{LS}=$ litter size; IX = index selection; UT = uterine capacity.

bTOR = total ovulation rate; TLS = total litter size; TOS = total ova success; ROR = right ovulation rate; LOR =left ovulation rate; RLS = right litter size; LLS = left litter size; ROS = right ova success; LOS = left ova success. 
Table 5. Simulated and observed phenotypic correlations for reproductive traits of the base generation ${ }^{a}$

\begin{tabular}{|c|c|c|c|c|c|c|c|c|c|}
\hline Trait $^{b}$ & TOR & TLS & TOS & ROR & LOR & RLS & LLS & ROS & LOS \\
\hline TOR & - & .45 & -.04 & .50 & .49 & .34 & .30 & -.03 & -.05 \\
\hline TLS & .44 & - & .86 & .33 & .13 & .72 & .69 & .68 & .70 \\
\hline TOS & -.14 & .82 & - & .09 & -.12 & 61 & .60 & .79 & .83 \\
\hline ROR & .49 & .25 & -.02 & - & -.51 & .70 & -.27 & -.07 & .14 \\
\hline LOR & .45 & .16 & -.11 & -.56 & - & -.38 & .57 & .05 & -.19 \\
\hline RLS & .32 & .70 & .57 & .64 & -.36 & - & -.01 & .62 & .34 \\
\hline LLS & .27 & .64 & .54 & -.33 & .60 & -.10 & - & .32 & .64 \\
\hline ROS & -.10 & .61 & .74 & -.22 & .12 & .58 & .23 & - & .36 \\
\hline LOS & -.12 & .60 & .74 & .16 & -.27 & .24 & .57 & .15 & - \\
\hline
\end{tabular}

aObserved correlations above diagonal (from Clutter et al., 1990) and simulated correlations below diagonal.

bTOR = total ovulation rate; TLS = total litter size; TOS = total ova success; ROR = right ovulation rate; LOR =left ovulation rate; RLS = right litter size; LLS = left litter size; ROS = right ova success; LOS = left ova success.

reported a value of .33. They did not report values for uterine capacity, but their estimates for ova success were much larger than those simulated. Clutter et al. (1990) reported a heritability of .15 for total ova success, but the simulation generated a population with a heritability of .06 . This low estimate is probably a function of the low heritability for uterine capacity. Heritability for total viable embryos, as expected, was smaller than the heritability for total ovulation rate (.19 vs .24). The higher heritability estimates reported by Clutter et al. (1990) could have been biased upward by other components because they were derived using covariances between colateral relatives, which could include some environmental contributions, whereas the simulation model considered only direct additive genetic effects.

Genetic correlations in the simulated and experimental data between total ovulation rate and total litter size were .71 and .81, respectively. The correlations also tended to agree within side. Between right and left ovulation rate, correlations in the observed and simulated data were .72 and 1.06 , and between right and left litter size, 1.33 and .97, respectively. However, even though the correlation between the simulated total ovulation rate and total ova success was -.30 , the correlation in the observed data was close to zero (.06). The correlation between simulated total ova success and total litter size also tended to agree with that in the observed (.45 and .60, respectively).

Phenotypic correlations among ovulation rate, ova success, and litter size were essentially the same as in Table 5. All correlations in simulated data involving viable embryos were similar to those with ovulation rate. Total ovulation rate and total viable embryos had high genetic and phenotypic correlations ( 1.0 and .87 , respectively). Genetic and phenotypic correlations in the simulated data between total uterine capacity and total ovulation rate or total viable embryos were essentially zero, agreeing with the value used (0.0) in the simulation. Correlations between total uterine capacity and total ova success or total litter size were high and positive, .96 and .70, and .70 and .64, respectively, for genetic and phenotypic estimates.

Based on these genetic correlations, one would predict that response to direct selection for litter size would be realized through increases in ovulation rate (and viable embryos) and uterine capacity, and from a much smaller increase in ova success. Direct selection for ovulation rate would increase litter size

Table 6. Simulated and observed phenotypic correlations for reproductive traits at Generation 13 of LS (litter size selection) ${ }^{a}$

\begin{tabular}{|c|c|c|c|c|c|c|c|c|c|}
\hline Trait $^{b}$ & TOR & TLS & TOS & ROR & LOR & RLS & LLS & ROS & LOS \\
\hline TOR & - & .51 & -.03 & .38 & .56 & .28 & .39 & .02 & -.05 \\
\hline TLS & .49 & - & .83 & .15 & .32 & .63 & .67 & .72 & .67 \\
\hline TOS & -.12 & .80 & - & -.06 & .03 & .56 & .52 & .85 & .81 \\
\hline ROR & .50 & .23 & -.07 & - & -.55 & .69 & -.47 & -.10 & .00 \\
\hline LOR & .46 & .24 & -.04 & -.54 & - & -.37 & .77 & .11 & -.04 \\
\hline RLS & .32 & .67 & .54 & .65 & -.35 & - & -.15 & .62 & .29 \\
\hline LLS & .32 & .64 & .51 & -.36 & .68 & -.14 & - & .33 & .57 \\
\hline ROS & -.10 & .61 & .76 & -.20 & .12 & .58 & .20 & - & .42 \\
\hline LOS & -.09 & .57 & .72 & .12 & -.20 & .20 & .55 & .15 & - \\
\hline
\end{tabular}

a Observed correlations above diagonal and simulated correlations below diagonal.

bTOR = total ovulation rate; TLS = total litter size; TOS = total ova success; ROR = right ovulation rate; LOR =left ovulation rate; RLS = right litter size; LLS = left litter size; ROS = right ova success; LOS = left ova success. 
Table 7. Estimated heritabilities (on diagonal) and genetic (above diagonal) and phenotypic (below diagonal) correlations for the simulated base population

\begin{tabular}{|c|c|c|c|c|c|c|c|c|c|c|c|c|c|c|c|}
\hline Trait $^{b}$ & TOR & TLS & TOS & TUC & TVE & ROR & LOR & RLS & LLS & ROS & LOS & RUC & LUC & RVE & LVE \\
\hline TOR & .24 & .71 & -.30 & .00 & 1.00 & 1.02 & 1.01 & .68 & .74 & -.25 & -.33 & -.01 & .01 & 1.00 & 1.02 \\
\hline TLS & .43 & .09 & .45 & .70 & .72 & .78 & .67 & .99 & .99 & .50 & .42 & .69 & .69 & .77 & .68 \\
\hline TOS & -.15 & .81 & .06 & .96 & -.30 & -.23 & -.38 & .49 & .41 & 1.00 & .99 & .95 & .92 & -.23 & -.37 \\
\hline TUC & .00 & .64 & .70 & .09 & .01 & .05 & -.04 & .71 & .69 & .98 & .92 & .98 & .97 & .06 & -.03 \\
\hline TVE & .87 & .50 & .00 & .00 & .19 & 1.02 & 1.01 & .69 & .74 & -.25 & -.32 & .01 & .02 & 1.01 & 1.01 \\
\hline ROR & .48 & .25 & -.03 & .00 & .42 & .05 & 1.06 & .74 & .82 & -.15 & -.28 & .03 & .07 & 1.00 & 1.06 \\
\hline LOR & .45 & .16 & -.11 & .00 & .39 & -.57 & .05 & .65 & .68 & -.36 & -.39 & -.03 & -.05 & 1.03 & 1.00 \\
\hline RLS & .30 & .69 & .56 & .43 & .35 & .64 & -.37 & .04 & .97 & .56 & .42 & .71 & .68 & .73 & .67 \\
\hline LLS & .27 & .63 & .52 & .42 & .31 & -.35 & .61 & -.12 & .04 & .41 & .41 & .66 & .69 & .80 & .68 \\
\hline ROS & -.11 & .61 & .74 & .54 & .03 & -.21 & .12 & .58 & .22 & .03 & .96 & 1.01 & .90 & -.16 & -.35 \\
\hline LOS & -.12 & .59 & .73 & .52 & .00 & .15 & -.27 & .24 & .56 & .15 & .04 & .87 & .93 & -.26 & -.38 \\
\hline RUC & .00 & .53 & .59 & .87 & .00 & .00 & .00 & .49 & .21 & .62 & .25 & .07 & .91 & .03 & -.02 \\
\hline LUC & .00 & .54 & .59 & .80 & .00 & .00 & .00 & .20 & .53 & .25 & .64 & .39 & .07 & .09 & -.05 \\
\hline RVE & .45 & .30 & .05 & .00 & .52 & .94 & -.53 & .68 & -.32 & -.08 & .14 & .00 & .00 & .04 & 1.03 \\
\hline LVE & .42 & .20 & -.04 & .00 & .48 & -.53 & .94 & -.34 & .65 & .11 & -.15 & .00 & .00 & -.50 & .05 \\
\hline
\end{tabular}

aStandard errors for heritability range from .004 to .013 .

bTOR =total ovulation rate; TLS =total litter size; TOS =total ova success; TUC =total uterine capacity; TVE =total viable embryos; ROR $=$ right ovulation rate; LOR =left ovulation rate; RLS = right litter size; LLS =left litter size; ROS =right ova success; LOS =left ova success; RUC = right uterine capacity; LUC = left uterine capacity; RVE = right viable embryos; LVE = left viable embryos.

through more viable embryos, uterine capacity would not change, but ova success would decrease. Direct selection for uterine capacity would increase ova success and litter size.

Simulated Selection. Simulated and observed cumulative selection differentials, realized heritabilities, and responses per generation for total number born are presented in Table 8. Because selection intensity in the simulated selection process was approximately the same as that used by Gion et al. (1990), cumulative selection differentials (CSD) were expected to match. For the LS and IX criteria, simulated and observed CSD agreed, but simulated CSD for the UT criterion was $29.2 \%$ greater than the observed CSD. A possible explanation for this difference is the large variability for uterine capacity used in the simulation. Because realized heritability is a function of response and CSD, simulated and observed results were expected to agree. Responses per generation in number born were .15 and .16 for LS, .17 and .18 for
IX, and .10 and .11 for UT for the experimental and simulated selections, respectively.

Simulated and observed responses of total ovulation rate, total ova success, total litter size, and total, right, and left uterine capacities after 13 generations of selection are presented in Table 9. Simulated responses for total ovulation rate and total litter size were slightly larger than those observed by Gion et al. (1990). The UT selection criterion created proportionally larger differences for the two traits. Simulated and observed total ova success agreed well for LS and UT. F or IX the simulation model created a very small negative change in total ova success (-.01), but the observed change in ova success was positive (.02). Our simulations predicted that selection based on the IX criterion would result in an extra increase in litter size of $14.3 \%$ compared with direct selection for litter size (LS criterion), and that selection based on the UT criterion would decrease response in litter size by $37.6 \%$. The relative differences in response realized in

Table 8. Cumulative selection differentials (CSD), heritability $\left(\mathrm{h}^{2}\right)$ estimated by regression of response in number born on CSD, and regression of response (R/gen) on generation number after 13 generations of selection using observed and simulated data ${ }^{a}$

\begin{tabular}{|c|c|c|c|c|c|c|}
\hline \multirow[b]{2}{*}{ Criterion ${ }^{b}$} & \multicolumn{2}{|c|}{$\mathrm{CSD}^{\mathrm{C}}$} & \multicolumn{2}{|c|}{$h^{2}$} & \multicolumn{2}{|c|}{$\mathrm{R} /$ gen $^{d}$} \\
\hline & Observed & Simulated & Observed & Simulated & Observed & Simulated \\
\hline LS & 21.68 & 20.57 & $.09 \pm .02$ & .10 & .15 & .16 \\
\hline IX & 19.30 & 20.88 & $.12 \pm .01$ & .11 & .17 & .18 \\
\hline UT & 17.51 & 22.63 & $.08 \pm .02$ & .06 & .10 & .11 \\
\hline
\end{tabular}

aObserved values are from Gion et al. (1990).

$\mathrm{b}_{\mathrm{LS}}=$ litter size; IX = index selection; UT = uterine capacity.

Index values for IX and number born for others.

dUsing deviations from LC. 
Table 9. Simulated (Sim) and observed (Obs) response in reproductive traits after 13 generations of selection ${ }^{\text {a }}$

\begin{tabular}{|c|c|c|c|c|c|c|c|c|c|}
\hline \multirow[b]{3}{*}{ Criterion ${ }^{b}$} & \multicolumn{9}{|c|}{ Trait $^{\mathrm{C}}$} \\
\hline & \multicolumn{2}{|c|}{ TOR } & \multicolumn{2}{|c|}{ TOS } & \multicolumn{2}{|c|}{ TLS } & \multirow{2}{*}{$\frac{\text { TUC }}{\text { Sim }}$} & \multirow{2}{*}{$\frac{\text { RUC }}{\text { Sim }}$} & \multirow{2}{*}{$\frac{\text { LUC }}{\operatorname{Sim}}$} \\
\hline & Obs & Sim & Obs & Sim & Obs & Sim & & & \\
\hline LS & 1.88 & 2.37 & .00 & .01 & 1.66 & 2.10 & 2.19 & 1.22 & .97 \\
\hline IX & 1.98 & 3.21 & .02 & -.01 & 1.97 & 2.40 & 1.60 & .89 & .71 \\
\hline $\mathrm{UT}^{\mathrm{d}}$ & .34 & .71 & .04 & .05 & .79 & 1.31 & 3.40 & 1.78 & 1.62 \\
\hline Base or LC & 12.27 & 13.22 & .82 & .80 & 9.98 & 10.54 & 16.30 & 8.91 & 7.39 \\
\hline
\end{tabular}

a Observed values are from Gion et al. (1990).

bLS = litter size; IX = index selection; UT = uterine capacity; LC = control

CTOR = total ovulation rate; TOS =total ova success; TLS = total litter size; TUC = total uterine capacity; RUC =right uterine capacity; LUC = left uterine capacity.

dintact females.

the mouse experiment were an increase of $18.7 \%$ and a decrease of $52.4 \%$, respectively. Part of these differences may be due to different ovulation rates. Relative to selection response with the LS criterion, simulation predicted that the IX criterion would have a $35.4 \%$ increase in total ovulation rate and the UT criterion a decrease of $70.0 \%$, but respective observed values were an increase of $5.3 \%$ and a decrease of $81.9 \%$. Although relative differences were sometimes quite large due to very small means, the absolute differences were not that large, and sampling error cannot be ruled out.

Simulated responses for total, right, and left uterine capacities were largest for UT, followed by LS and IX. As expected due to the high correlation, responses in uterine capacity between sides, within criterion of selection, were very similar. A slightly higher response on the right side was observed. These responses in uterine capacity were not expected to match with responses generated in the phenotypic model (Table $1)$. In the phenotypic model, means for uterine capacity were generated in order to mimic the specific means for litter size at Generation 13.

\section{Discussion}

Although some adaptations were necessary to implement in mice the simulation model proposed for pigs by Bennett and Leymaster (1989), the models in both studies are essentially the same. In both simulations, uterine capacity was assumed to be the maximum number of fetuses a dam can carry to term. Although our estimates of uterine capacity in mice were proportionally different for explaining litter size than the ones estimated for pigs by Bennett and Leymaster (1989), both studies were able to mimic observed results. The differences between species start in the relative value of uterine capacity to ovulation rate. Bennett and Leymaster (1989) generated a value for uterine capacity that was $5.6 \%$ smaller than ovulation rate. In our simulation initial means for total ovulation rate and total uterine capacity were
13.20 and 16.28, respectively. Apparently, uterine capacity is not the most limiting factor in our mice population.

Comparison of the simulation of litter size in mice presented here and the simulation in pigs by Bennett and Leymaster (1989, 1990a,b) is enhanced by an attempt to overcome differences between mice and pigs resulting from the different forms of uteri. To do this, we used data from the simulated base generation. If right ovulation rate was greater than left, then the right-side data were used. Likewise, if the left ovulation rate was greater, left-side data were used as the single measure of these characteristics for an animal. If left and right sides were equal for ovulation rate, the average of the two sides was used.

Table 10 contains statistics for simulated mouse data using only the side with the larger ovulation rate and the corresponding statistics for simulated pig data presented by Bennett and Leymaster (1989). For the pig data, the means for ovulation rate and uterine capacity were nearly the same. The same is true for mice when only considering the side with the larger ovulation rate; this is in contrast to the total mouse data, for which the simulated mean for total uterine capacity (16.30) exceeded the mean for total ovulation rate (13.22). The correlations between components of litter size also agreed fairly well when comparing the data on pigs to the data on the side of mice with the greater ovulation rate. Because the mouse has a split uterus and ovulations are binomially distributed, it must have larger uterine capacity of each side, hence larger total uterine capacity relative to ovulation rate, to optimize litter size. Bennett and Leymaster (1990a) hypothesized that pigs naturally or artificially selected for litter size would have similar uterine capacity and ovulation rate. Similar reasoning applies to the side with higher ovulation in mice. Differences in the anatomy of mice help to validate this hypothesis.

Genetic parameters for uterine capacity are scarce in the literature. The only published heritabilities found are those from the selection experiment with 
Table 10. Phenotypic statistics for simulated litter size and its components in mice, considering only the side of the reproductive tract with the larger ovulation rate, and in pigs ${ }^{\mathrm{a}}$

\begin{tabular}{|c|c|c|c|c|c|c|}
\hline \multirow[b]{2}{*}{ Characteristic $^{b}$} & \multicolumn{3}{|c|}{ Mice } & \multicolumn{3}{|c|}{ Pigs } \\
\hline & Mean & SD & $\mathrm{CV}$ & Mean & SD & $\mathrm{CV}$ \\
\hline & & & $-U n$ & stics - & & \\
\hline OR & 8.05 & 1.53 & 19.0 & 12.69 & 2.38 & 18.8 \\
\hline UC & 8.21 & 3.69 & 45.0 & 11.98 & 4.20 & 35.1 \\
\hline OS & .77 & .23 & 30.0 & .74 & .18 & 24.2 \\
\hline LS & 6.16 & 2.06 & 33.5 & 9.25 & 2.59 & 28.0 \\
\hline OR and UC & & .02 & & & .00 & \\
\hline OR and OS & & -.20 & & & -.22 & \\
\hline OR and LS & & .38 & & & .47 & \\
\hline UC and OS & & .75 & & & .67 & \\
\hline UC and LS & & .71 & & & .61 & \\
\hline OS and LS & & .82 & & & .74 & \\
\hline
\end{tabular}

aData from pig simulation taken from Bennett and Leymaster (1989).

${ }^{\mathrm{b}} \mathrm{OR}=$ ovulation rate; UC = uterine capacity; OS = proportion of ova resulting in fully formed young; LS =litter size or number fully formed young.

mice used as a basis for this study, .08 by Gion et al. (1990) and Kirby and Nielsen (1993), and .05 by Clutter et al. (1994), and from divergent selection with rabbits, $.20 \pm .12$ by Bolet et al. (1994). Recent heritability estimates (Nielsen et al., 1996) from a REML analysis using the mouse data set of Clutter et al. (1994) are .20 to .33 for left uterine capacity and .13 to .19 for right uterine capacity. Given the magnitude of the SE, a true value in the range of .15 to .20 for mice is possible. Bennett and Leymaster (1989, 1990a,b) assumed heritabilities of .15 and .20 in their simulation study with pigs. In general, our estimates of genetic correlations involving total uterine capacity agree with the estimates reported by Bennett and Leymaster (1989). Their estimates of correlation using heritability of either .15 or .20 for uterine capacity were very similar. They estimated genetic correlations of .91 between total uterine capacity and ova success, and .71 and .75 between total uterine capacity and litter size, whereas our corresponding estimates were .96 and .70. Phenotypic correlations are also similar; their estimates between total uterine capacity and ova success or litter size were .67 and .61, whereas ours were .70 and .64, respectively.

A greater mean for right uterine capacity is in agreement with results reported for other traits in this same selection experiment (Clutter et al., 1990; Gion et al., 1990; Al-Shorepy et al., 1992; and Clutter et al., 1994), and with other mouse experiments (Falconer et al., 1961; McLaren, 1963; Wiebold and Becker, 1987). Uterine capacity measured as number born to unilaterally ovariectomized females in all selection criteria at Generation 22 and 23 of this experiment was also greater on the right side of the reproductive tract (Clutter et al., 1994).

As mentioned before, correlations in the simulated data involving ova success agreed the least with observed correlations. Our simulation predicted a phenotypic correlation of -.15 and a genetic correlation of -.30 between total ovulation rate and ova success, which were different from those reported by Clutter et al. (1990; .06 and -.04 , respectively). Ribeiro et al. (1996) estimated a phenotypic correlation of -.16 between ovulation rate and embryonic survival to $d 6$ in these same lines. Phenotypic correlation values of -.42 and -.32 were reported for pigs by J ohnson et al. (1984) and Christenson et al. (1987), respectively. The simulated value for pigs by Bennett and Leymaster (1989) was -.22. The genetic correlation between these two traits for pigs has been reported to be -.75 (J ohnson et al., 1984) and -.56 (Neal et al., 1989). Bennett and Leymaster (1989) estimated genetic correlations of -.40 and -.36 when using values of .15 or .20 for heritability of uterine capacity in their simulations.

The heritability of ova success has generally been estimated to be smaller than the heritability for litter size. Our heritability for total ova success (.06) in the simulated base population was smaller than those reported for pigs (.15 and .16) by J ohnson et al. (1984) and Neal et al. (1989). Bennett and Leymaster (1989) reported values of .08 and .11 in their simulations. In an experiment with unilaterally ovariectomized rabbits, Bolet et al. (1994) reported values of .11 to .18 for heritability of embryonic and total prenatal survival; however, the heritability of fetal survival was not different from zero. Our value of heritability for litter size (.09) agreed with those cited in the literature. Reported heritabilities of litter size in mice vary substantially from publication to publication, ranging from .08 to .23 (Falconer, 1960; Bradford, 1968; J oakimsen and Baker, 1977; Bakker et al., 1978; Eisen, 1978). Rochambeau et al. (1994) reported heritabilities of .06 and .07 for total number 
born alive in rabbits. In pigs most estimates are approximately .10 (Haley et al., 1988).

Although the heritability for total ovulation rate used in our simulation was $24.2 \%$ smaller than the one estimated by Clutter et al. (1990), it was still in the range found in the literature. Land and Falconer (1969) reported a value of .22 for heritability of natural ovulation rate estimated from the correlation between paternal half-sibs and realized heritabilities of .31 and .22, respectively, for natural and induced ovulation rate selection lines. Bradford (1969) reported an even lower heritability, slightly less than .10 , in a line selected on natural ovulation rate. In pigs, estimates of heritability also vary considerably. $\mathrm{Neal}$ et al. (1989) reported a value estimated by regression of daughter on dam of .17, but J ohnson et al. (1984) reported a value from a selection experiment of .45.

Although responses in ovulation rate, ova success, and litter size after 13 generations of simulated selection were not exactly the same as those observed by Gion et al. (1990), the ranking for the three criteria matched very well. The model predicts that an increase in litter size and a minimal change in ova success, resulting from selection using LS criterion occurs due to increases in ovulation rate and uterine capacity. This same result was predicted by Bennett and Leymaster (1990b). The simulation model predicts that the larger increase in litter size observed using the IX criterion compared with the LS criterion was due to a proportionally larger change in ovulation rate relative to uterine capacity (3.21 vs 1.60$)$ than what was observed in LS (2.37 vs 2.19). So, the IX criterion puts more emphasis on the most limiting component (i.e., ovulation rate). This supports the remarks made by J ohnson et al. (1984) and Bennett and Leymaster (1990b) that direct selection for litter size (the natural index) does not balance the components most efficiently. However, simulation results for IX agreed only partially with those observed. The model predicted a small decrease in ova success, whereas a small improvement was observed. It is difficult to determine whether this discrepancy is due to sampling error or whether the increase in total uterine capacity was proportionally larger than what was predicted by the simulation model.

Although genetic and environmental correlations between ovulation rate and uterine capacity were set to zero in our simulation, the model predicted an increase in ovulation rate in the UT criterion. Bennett and Leymaster (1990b) did not observe a positive correlated response in ovulation rate following simulated selection for uterine capacity. Clutter et al. (1994) measured uterine capacity, in all criteria, as the number of fetuses at $17 \mathrm{~d}$ in unilaterally ovariectomized females at Generations 22 and 23, and they speculated that uterine capacity in the UT criterion was probably not fully expressed; this would explain an unintentional selection for ovulation rate in the UT criterion.

As expected, simulated response in total uterine capacity was greatest in the UT criterion; however, this result does not agree with results reported by Clutter et al. (1994). They reported the greatest mean capacity for the LS selection followed by IX and then UT. But, as pointed out by them and mentioned above, uterine capacity in the UT criterion during the process of selection was probably not fully expressed in all animals. To accurately measure uterine capacity, the number of fetuses must be independent of ovulation rate, as proposed by Christenson et al. (1987). Although a reduction in the phenotypic correlation between ovulation rate and number of fetuses was observed in the unilaterally ovariectomized females compared with intact females, it was still much greater than zero: .31 and .39, respectively, for left and right sides of the reproductive tract (Clutter et al., 1994). The similarity of responses in right and left uterine capacity, as simulated here, does not agree with results reported by Clutter et al. (1994). However, they also found greater responses in the right side following selection on all three criteria, but the responses observed by them were proportionally larger.

In summary, the model integrating ovulation rate, potential embryonic viability, and uterine capacity was able to reproduce results observed in the population of mice described. The ability of this model to imitate results with mice gives support to the corresponding model in swine (Bennett and Leymaster, 1989). Although uterine capacity was not considered the most limiting component in this population of mice, its use in an index with ovulation rate may be warranted.

\section{Implications}

Although uterine capacity was not considered the most limiting component in mice, it was important for explaining part of the observed variability in litter size. Its use, along with the other components of litter size in a selection program, is expected to improve response over direct selection for litter size. This may also be true in livestock species, and success of its use will depend partly on the accuracy of the estimated genetic parameters and on our ability to measure uterine capacity.

\section{Literature Cited}

Al-Shorepy, S. A., A. C. Clutter, R. M. Blair, and M. K. Nielsen. 1992. Effects of three methods of selection for litter size in mice on pre-implantation embryonic development. Biol. Reprod. 46: 958.

Bakker, H., J . H. Wallinga, and R. D. Politiek. 1978. Reproduction and body weight of mice after long-term selection for large litter size. J. Anim. Sci. 46:1572. 
Bennett, G. L., and K. A. Leymaster. 1989. Integration of ovulation rate, potential embryonic viability and uterine capacity into a model of litter size in swine. J. Anim. Sci. 67:1230.

Bennett, G. L., and K. A. Leymaster. 1990a. Genetic implications of a simulation model of litter size in swine based on ovulation rate, potential embryonic viability and uterine capacity: I. Genetic theory. J. Anim. Sci. 68:969.

Bennett, G. L., and K. A. Leymaster. 1990b. Genetic implications of a simulation model of litter size in swine based on ovulation rate, potential embryonic viability and uterine capacity: II. Simulated selection. J. Anim. Sci. 68:980.

Bolet, G. 1986. Timing and extent of embryonic mortality in pigs, sheep and goats: Genetic variability. In: J. M. Sreenan and M. G. Diskin (Ed.) Embryonic Mortality in Farm Animals. pp 12-43. Martinus Nijhoff Publishers, Dordrecht, The Netherlands.

Bolet, G., M. A. Santacreu, M. J . Argente, A. Climent, and A. Blasco. 1994. Divergent selection for uterine efficiency in unilaterally ovariectomized rabbits. I. Phenotypic and genetic parameters. Proc. 5th World Congr. Genet. Appl. Livest. Prod. 19:261.

Bradford, G. E. 1968. Selection for litter size in mice in the presence and absence of gonadotropin treatment. Genetics 58:283.

Bradford, G. E. 1969. Genetic control of ovulation rate and embryo survival in mice. I. Response to selection. Genetics 61:905.

Bradford, G. E. 1979. Genetic variation in prenatal survival and litter size. Proc. XIII Biennial Symp. on Anim. Reprod. J . Anim. Sci. 49(Suppl. 2):66.

Christenson, R. K., K. A. Leymaster, and L. D. Young. 1987. J ustification of unilateral hysterectomy-ovariectomy as a model to evaluate uterine capacity in swine. J. Anim. Sci. 65:738.

Clutter, A. C., Y.L.K. Kirby, and M. K. Nielsen. 1994. Uterine capacity and ovulation rate in mice selected 21 generations on alternative criteria to increase litter size. J . Anim. Sci. 72:577.

Clutter, A. C., M. K. Nielsen, and R. K. J ohnson. 1990. Alternative methods of selection for litter size in mice: I. Characterization of base population and development of methods. J. Anim. Sci. 68:3536.

Eisen, E. J . 1978. Single-trait and antagonistic index selection for litter size and body weight in mice. Genetics 88:781.

Falconer, D. S. 1960. The genetics of litter size in mice. J. Cell. Comp. Physiol. 56(Suppl. 1):153.

Falconer, D. S., R. G. Edwards, R. E. Fowler, and R. C. Roberts. 1961. Analysis of differences in the number of eggs shed by the two ovaries of mice during natural oestrus or after superovulation. J. Reprod. Fertil. 2:418.
Gama, L. T., K. G. Boldman, and R. K. J ohnson. 1991. Estimates of genetic parameters for direct and maternal effects on embryonic survival in swine. J. Anim. Sci. 69:4801.

Gion, J. M., A. C. Clutter, and M. K. Nielsen. 1990. Alternative methods of selection for litter size in mice: II. Response to thirteen generations of selection. J. Anim. Sci. 68:3543.

Haley, C. S., E. Avalos, and C. Smith. 1988. Selection for litter size in the pig. Anim. Breed. Abstr. 56:317.

J oakimsen, O., and R. L. Baker. 1977. Selection for litter size in mice. Acta Agric. Scand. 27:301.

J ohnson, R. K., D. R. Zimmerman, and R. J . Kittok. 1984. Selection for components of reproduction in swine. Livest. Prod. Sci. 11: 541.

Kirby, Y. K., and M. K. Nielsen. 1993. Alternative methods of selection for litter size in mice: III. Response to 21 generations of selection. J. Anim. Sci. 71:571.

Land, R. B., and D. S. Falconer. 1969. Genetic studies of ovulation rate in the mouse. Genet. Res. (Camb.) 13:25.

McLaren, A. 1963. The distribution of eggs and embryos between sides in the mouse. J. Endocrinol. 27:157.

MCLaren, A., and D. Michie. 1954. Transmigration of unborn mice. Nature (Lond.) 174:844.

Neal, S. M., R. K. J ohnson, and R. J . Kittok. 1989. Index selection for components of litter size in swine: Response to five generations of selection. J. Anim. Sci. 67:1933.

Nielsen, M. K., Y. L. Kirby, and A. C. Clutter. 1996. Estimates of heritabilities and genetic and environmental correlations for left- and right-side uterine capacity and ovulation rate in mice. J. Anim. Sci. 74:529.

Pérez-Enciso, M., J. L. Foulley, L. Bodin, and J. P. Poivey. 1994. Genetic implications of a bivariate threshold model for litter size components. J. Anim. Sci. 72:2775.

Ribeiro, E. L. de A., M.A.J . van Engelen, and M. K. Nielsen. 1996. Embryonal survival to 6 days in mice selected on different criteria for litter size. J. Anim. Sci. 74:610.

Rochambeau, H. de, G. Bolet, and F. Tudela. 1994. Long term selection. Comparison of two rabbit strains. Proc. 5th World Congr. Genet. Appl. Livest. Prod. 19:257.

SAS. 1990. SAS Language: Reference (Version 6, 1st Ed.). SAS I nst. Inc., Cary, NC.

Villanueva, B., and B. W. Kennedy. 1990. Effect of selection on genetic parameters of correlated traits. Theor. Appl. Genet. 80: 746.

Wiebold, J . L., and W. C. Becker. 1987. Inequality in function of the right and left ovaries and uterine horns of the mouse. J. Reprod. Fertil. 79:125. 